\section{Estudo \\ CoDebate}

em Crestão

Planejamento
Revista Estudo \& Debate, Lajeado, v. 27, n. 3, 2020. ISSN 1983-036X DOI: http://dx.doi.org/10.22410/issn.1983-036X.v27i3a2020.2514

\title{
PROJETOS PROFISSIONAIS DE JOVENS ESTUDANTES DE CURSO TÉCNICO PROFISSIONALIZANTE EM AGROPECUÁRIA NO RS
}

\author{
Rosani Marisa Spanevello${ }^{1}$, Mariele Boscardin², Vitória Benedetti De Toledo ${ }^{3}$, \\ Adriano Lago ${ }^{4}$
}

\begin{abstract}
Resumo: Objetivou-se com a realizaçáo deste estudo analisar e descrever os projetos profissionais de jovens estudantes de curso técnico em Agropecuária no município de Palmeira das Missões, estado do Rio Grande do Sul. Para a obtençáo dos dados deste estudo, realizou-se um levantamento com um total de 51 jovens os quais foram obtidos por meio da aplicaçáo de um questionário autoaplicável e anônimo. Os dados coletados foram tabulados e analisados a partir do Software Statistical Package for the Social Sciences. Em relação aos projetos profissionais identificou-se que $35,29 \%$ dos jovens pretende residir no meio rural, com ocupaçóes urbanas, $27,59 \%$ pretende se instalar como agricultor no meio rural, $21,57 \%$ pretendem residir e trabalhar no meio urbano com vínculo no rural e 11,76\% possuem outras opções como projetos profissionais. Deste modo, embora os jovens possuam origem no rural e estejam vinculados a um curso de formaçáo agropecuária, a maior parte dos entrevistados busca um projeto voltado a ocupaçáo urbana, no entanto, ainda pretendem ter o rural como local de moradia.
\end{abstract}

Palavras-chave: Agricultura Familiar; Jovens; Projetos profissionais.

1 Professora no Programa de Pós-Graduação em Agronegócios- UFSM campus Palmeira das Missōes. Mestre em Extensão rural pela UFSM e Doutora em Desenvolvimento Rural pela UFRGS. Graduada em Agronomia pela UFSM.

2 Mestre em Desenvolvimento Rural pela UFRGS. Graduada em Zootecnia pela UFSM campus Palmeira das Missões.

3 Graduanda em Administração pela UFSM campus Palmeira das Missões.

4 Professor no Programa de Pós-Graduação em Agronegócios- UFSM campus Palmeira das Missóes. Mestre em Extensão Rural pela UFSM e doutor em Agronegócio pela UFRGS. Graduado em agronomia pela UFSM. 


\title{
PROFESSIONAL PROJECTS OF YOUNG STUDENT \\ PROFESSIONALIZING TECHNICAL COURSE IN AGROPECUARIA IN RS
}

\begin{abstract}
The objective was to carry out an analysis study and describe the projects of young students of technical course in Agriculture in the municipality of Palmeira das Missóes, state of Rio Grande do Sul. To obtain the data for this study, a survey was carried out with a total of 51 young people, which were obtained through the application of a self-administered and anonymous questionnaire. The collected data were tabulated and analyzed using the Statistical Package for the Social Sciences Software. Regarding professional projects, it was identified that $35.29 \%$ of young people intend to live in rural areas, with urban occupations, $27.59 \%$ intend to settle as a farmer in rural areas, $21.57 \%$ intend to live and work in urban areas with rural and $11.76 \%$ have other options such as professional projects. Thus, although the young people have a rural background and are linked to an agricultural training course, most of the interviewees are looking for a project aimed at urban occupation, however, they still intend to have the rural as a place of residence.
\end{abstract}

Keywords: Family farming; Young; Professional projects.

\section{INTRODUÇÁO}

Tradicionalmente, os estudos em torno da temática juventude, tem predominantemente privilegiado os jovens dos grandes centros urbanos em detrimento dos jovens rurais (Carneiro, 2005). Sendo assim, os jovens rurais tornaram-se alvo de discussóes somente a partir de 1990, período no qual, pesquisadores brasileiros, discorrem sobre a ocorrência de alguns fenômenos no meio rural. Estes fenômenos dizem respeito aos processos de envelhecimento e masculinização da população rural (CAMARANO; ABRAMOVAY, 1999; ANJOS; CALDAS, 2005), os quais são ocasionados pela elevada migração para o meio urbano deste público, os jovens rurais.

A esse respeito, Troain e Breitenbach (2018), ressaltam que a partir de entâo, os estudos em torno dos jovens rurais, dedicaram-se, sobretudo, a estudar a problemática da sucessão geracional e de açôes com vistas a solucioná-las.

Frente a esta dicotomia, que há, entre os jovens rurais e os jovens urbanos, Breitenbach e Corazza (2019), destacam que o jovem rural, possui oportunidades distintas e muitas vezes reduzidas quando comparados com jovens do meio urbano. Deste modo, o jovem rural visualiza na migraçáo a busca por melhores oportunidades de estudo e trabalho, com vistas a buscar uma melhor qualidade de vida.

Para Matte e Machado (2016), dentre os principais fatores que influenciam no processo de migração, destacam-se dentre outros fatores, a comparação entre os meios urbano e rural, as desigualdades de gênero, o acesso ao estudo, a expectativa profissional e os projetos futuros.

A respeito dos últimos aspectos, Troain e Breitenbach (2018), comentam ainda que, ao mesmo tempo em que os jovens são agentes de transformação, eles precisam ser formados para encontrar e assumir seu papel social. No meio rural, e em relação as atividades agrícolas e o gerenciamento das propriedades, Breitenbach e Corazza (2019), ressaltam a importância do jovem realizar estudo em áreas ligadas a agricultura a fim de se profissionalizar. 
Contudo, estudos anteriores revelam que, a falta de reconhecimento dos pais pelo conhecimento dos filhos e do trabalho por eles realizado acaba influenciando em seus projetos profissionais (FOGUESATTO; MACHADO, 2016; SPANEVELLO et al., 2011).

Diante deste contexto, tem- se como questáo norteadora deste estudo, os projetos e expectativas profissionais futuros de jovens rurais, estudantes de Curso Técnico Profissionalizante. Visto que, os projetos profissionais dos mesmos, apresentam-se como uma importante questâo acerca da temática da agricultura, com base no relevante papel que ocupam na reprodução deste segmento.

Ao abordar a expressão projetos, Velho (2003) cita Alfredo Schutz que desenvolveu esta noção e a conceituou como uma "conduta organizada para atingir finalidades específicas". Ao complementar a expressão, Velho (2003) ressalta que os projetos estâo imbricados intrinsecamente a ideia de individuo sujeito e que os mesmos podem ser expressos por meio de conceitos, palavras e categorias.

Adicionalmente a estes conceitos, projetos existem como maneiras de se expressar, articular interesses, objetivos, sentimentos a aspiraçóes para o mundo. Sendo assim, projetos não são abstratamente racionais, mas resultado consciente que emergem a partir do campo de possibilidades em que o sujeito está inserido (VELHO, 2003). Weisheimer (2007) define ainda projetos como uma forma de antecipar coincidentemente o futuro pretendido por meio de açôes que orientem sua conduta.

Ao falar sobre os projetos de jovens rurais, Carneiro (1999) salienta a assimetria que há entre os projetos e as atividades que o jovem realiza. Deste modo, na concepção de Weisheimer (2007) os projetos profissionais de jovens rurais traduzem em muitas situaçóes a avaliação a respeito da agricultura, assim como suas visôes das possibilidades de reprodução das unidades familiares, e seus propósitos de permanecer nesta atividade. Cabe destacar ainda que os projetos individuais dos jovens sáo reflexos muitas vezes dos projetos coletivos de suas famílias e suas relaçôes.

Para Carneiro (1999), os jovens rurais referem-se a uma categoria social fortemente afetada pelas mudanças ocorridas no meio rural. Com estas mudanças, as quais tornaram o rural como um espaço multisetorial, conforme destacado pioneiramente por autores como Silva (1997) e Kageyama (2008), ampliam-se os projetos dos jovens, os quais tradicionalmente se restringiam basicamente a ocupação agrícola.

Com a ampliação das possibilidades, Boscardin e Conterato (2017) comentam que ocorre o distanciamento dos jovens rurais das atividades agrícolas, a busca por outras estratégias laborais, e maior instrução formal. A respeito deste último aspecto, cabe dizer que, no momento em que os jovens rurais atingem níveis mais elevados de escolaridade, os mesmos passam a repensar seus projetos profissionais relacionados a ocupação agrícola.

A este respeito, Moraes, Binotto e Borges (2017), expóem que os pais exercem importante influência no que se refere as motivaçóes para que os filhos prossigam seus estudos relacionados a educação agrícola, visto que, o aprendizado no gerenciamento das propriedades ampliará o desejo de que os mesmos permaneçam atuando nas propriedades. Os autores comentam ainda que, outra importante ação é a preparação dos pais para 
receber os filhos após a conclusão dos estudos, aceitando novas ideias e permitindo que estes apliquem seus conhecimentos.

Dentre este universo de possibilidades propiciadas pelas mudanças ocorridas no meio rural, as atividades não agrícolas, tais como a agroindustrialização de matérias primas e o turismo rural têm se tornado importante alternativa geradora de renda para os residentes deste local em especial para os jovens e para as mulheres (SPANEVELLO et al., 2019).

Moraes, Binotto e Borges (2017), por meio de uma análise da literatura acerca das expectativas dos jovens rurais, salientam que, o acesso ao mercado de trabalho fora do setor agrícola em busca de qualidade de vida superior é um fator que influenciará nos projetos profissionais dos jovens rurais quanto a sua permanência ou não neste local. Considerando este aspecto, o exercício de atividades ocupacionais no meio urbano e a residência em áreas rurais também podem ser considerados como um projeto profissional dos jovens rurais que tem emergido na atualidade.

Este artigo tem como objetivo, analisar os projetos profissionais de jovens estudantes de curso técnico em Agropecuária no município de Palmeira das Missões, estado do Rio Grande do Sul. De acordo com Salvaro, Quadros e Estevan (2016), no contexto brasileiro, os cursos Técnicos em Agropecuária se inserem no âmbito da Educação Profissional de Nível Médio.

Para a obtenção dos dados, realizou-se um levantamento com um total de 79 jovens que estavam cursando o referido curso. Posteriormente, e para efeitos deste estudo, selecionou-se 51 destes, os quais eram filhos de agricultores, e estavam vinculados as atividades agrícolas. As informaçóes foram obtidas por meio da aplicação de um questionário autoaplicável e anônimo com questóes fechadas, referentes a caracterização socioeconômica e perspectivas e projetos profissionais futuros. Os dados e informaçóes geradas na pesquisa foram organizados e analisados através do Software Statistical Package for the Social Sciences (SPSS).

Este trabalho divide-se em quatro seções a contar com esta introdução. $\mathrm{Na}$ segunda seção apresenta-se uma breve revisão de literatura abordando os projetos profissionais de jovens rurais. $\mathrm{Na}$ terceira seçáo, encontra-se os resultados e discussóes acerca do estudo e sumariza-se este trabalho com as consideraçóes finais na quarta seção.

\section{JOVENS ESTUDANTES DO CURSO TÉCNICO EM AGROPECUÁRIA}

A análise a seguir contempla informações referentes aos jovens, bem como a propriedade rural dos mesmos, analisando questóes como distribuição dos jovens por sexo, idade, estado civil, local de residência, entre outras questóes. Além de tamanho da propriedade, atividades agropecuárias realizadas pela família, renda e participação do jovem nas atividades realizadas.

Os jovens rurais que fazem parte do estudo são estudantes do curso técnico profissionalizante em Agropecuária. Para Salvaro, Quadros e Estevan (2016), o processo de ensino e aprendizagem de atividades agropecuárias, especialmente pela profissionalização técnica, emerge como central na escolha do mesmo. Por outro lado, os autores comentam 
que, para os jovens que não pretendem se estabelecer no meio rural, o curso técnico, pode ser visualizado como um degrau de acesso à continuidade dos estudos.

Os jovens são oriundos de 24 municípios distintos, dos estados do Rio Grande do Sul e Santa Catarina, porém, se destaca na representação o município de Palmeira das Missóes, sede da escola, com 23,53 \% dos jovens participantes.

No que diz respeito à distribuição dos jovens quanto ao sexo, o masculino predominou, com $90,20 \%$ da amostra. Este fato pode ser explicado pelo curso em questáo ser do ramo agrícola, havendo menor predisposição das mulheres em atuar neste segmento.

Breitenbach e Corazza (2019), concluem que a desigualdade de gênero existente nos cursos das ciências agrárias ainda é observada visto que embora as jovens do sexo feminino vêm conquistando seu espaço ainda predomina jovens do sexo masculino nestes cursos.

Em relação à distribuição dos jovens por idade, 60,78\% possuem entre 16 e 17 anos. Sobre o estado civil, $94,12 \%$ são solteiros e $90,20 \%$ residem com seus pais.

Em relação à quantidade de terra da família dos jovens, 29,41\% declararam possuir entre 11 e 20 hectares, 19,61\% possuem área inferior a 10 hectares, outros 13,73\% possuem de 21 a 30 hectares. Por outro lado, destaca-se ainda 13,73\% das famílias que possuem acima de 141 hectares de área. Sendo que a média das propriedades gira em torno de 104,46 hectares.

Entre as atividades, desenvolvidas pelas famílias dos jovens, destacam-se os cultivos de grãos $(78,43 \%)$, bovinocultura de leite $(50,98 \%)$ e bovinocultura de corte $(27,45 \%)$. Ressalta-se ainda, que $43,14 \%$ das propriedades possuem empregados para realizarem as atividades. A renda agrícola é a mais representativa para a família, totalizando entre 2 e 4 salários mínimos para $43,15 \%$ das famílias.

Sobre a participação do jovem nas rendas oriundas das atividades agropecuárias realizadas pela família, os jovens declararam que, em 68,63\% dos casos, os pais centralizam os rendimentos. Por outro lado, em somente $13,73 \%$ das famílias, a renda é dividida entre todos os membros. Deste modo, $49,02 \%$ dos jovens declararam pedir dinheiro para os pais sempre que precisarem.

A participação das jovens do sexo feminino no fator renda é ainda mais restrito, tendo em vista que $60 \%$ declararam pedir dinheiro para os pais sempre que precisarem. Por outro lado, somente $20 \%$ afirmaram receber periodicamente uma quantia para despesas pessoais.

Coradini (2008), ao analisar o fator renda em seu estudo, constatou resultados semelhantes, visto que os jovens somente têm acesso à renda familiar quando solicitam aos seus pais. $\mathrm{O}$ autor verificou ainda que em restritas situaçóes, os jovens recebem uma quantia em dinheiro periodicamente.

No que diz respeito a tomada de decisão relacionada as atividades agrícolas, constatou que o pai é quem toma a maior parte das decisóes sobre a realização da compra de insumos $(72,55 \%)$, sobre as decisóes do que plantar $(50,98 \%)$ e venda da produção agropecuária $(60,78 \%)$. É também a figura do pai que em maior parte das situaçóes entra em contato com o técnico $(60,78 \%)$. 
Os resultados demonstraram ainda que a participação da mulher, no caso a mãe, é expressiva somente no âmbito das decisóes referentes a realização das compras da casa (39, 24\%). Ou seja, embora que, o trabalho da mulher passou a ser reconhecido, e elas vêm assumindo sua autonomia em tomar decisóes, as decisóes da figura masculina tende a predominar, cabendo as mulheres acatá-las. Essa desigualdade de gênero é ainda mais preponderante na relação pais e filhas, visto que a participação das filhas mulheres é um tanto quanto reduzida nas decisóes da propriedade, o que acaba acentuando a saída das filhas das propriedades rurais.

A reduzida participação das jovens rurais na propriedade também se torna evidente ao analisar variáveis distintas conforme apresentado na tabela 01 .

Tabela 01: Variáveis referentes a participação dos jovens na propriedade.

\begin{tabular}{l|c|c}
\hline \multicolumn{1}{c|}{ Variáveis } & \multicolumn{2}{c}{ Sexo } \\
\cline { 2 - 3 } & Feminino & Masculino \\
\hline $\begin{array}{l}\text { Recebe remuneração em dinheiro por minha participação no } \\
\text { trabalho familiar agrícola }\end{array}$ & $0,00 \%$ & $58,70 \%$ \\
\hline Bloco de produtor rural em seu nome & $0,00 \%$ & $15,22 \%$ \\
\hline Nome consta no bloco do produtor rural de meu pai ou mãe & $0,00 \%$ & $21,74 \%$ \\
\hline Possui área de terra em seu nome & $20,00 \%$ & $21,74 \%$ \\
\hline Possui conta corrente em seu nome & $0,00 \%$ & $30,43 \%$ \\
\hline Possui conta poupança em seu nome & $40,00 \%$ & $50,00 \%$ \\
\hline Possui financiamento em seu nome & $0,00 \%$ & $4,35 \%$ \\
\hline
\end{tabular}

Fonte: Elaborado pelos autores (2020).

Como se pode constatar as jovens mulheres não recebem remuneração em dinheiro pela participação no trabalho agrícola familiar, enquanto que 58,70\% dos jovens recebem. As jovens também não possuem bloco de produtor rural, enquanto que $15,22 \%$ dos jovens possuem, bem como, $21,74 \%$ possuem bloco de produtor rural em conjunto com os pais. A participação das jovens ainda é nula ao serem questionadas sobre a existência de contas correntes em seus nomes, enquanto que 30,43\% dos jovens do sexo masculino possuem.

Os resultados apresentados confirmam o que a literatura explica em relação as questóes de gêneros nas propriedades rurais, dado que, os homens possuem uma participação mais expressiva nas atividades e administração da propriedade. Em pesquisa realizada por Breitenbach e Corazza (2019), constatou-se que os jovens rurais do sexo masculino possuem maiores incentivos e estímulos e desejo de serem gestores e sucessores das propriedades rurais. Desta forma, esses fatores acabam influenciando nos projetos profissionais dos jovens, os quais serão apresentados na próxima seção.

Ainda se tratando de expectativas profissionais e futuras, os jovens foram questionados sobre futuros investimentos, caso tivessem condições. Sendo assim, foi possível constatar que $45,10 \%$ investiriam em estudos e formação para o mercado de trabalho rural, 35,9\% compraria terras e equipamentos agrícolas. Estes achados talvez indicariam que, muitos jovens acabam optando por buscar oportunidades de trabalho no meio urbano, visto que não teriam condiçóes de investir no meio rural. 
A respeito das expectativas futuras, os jovens foram questionados sobre planos em dar continuidade aos estudos após a conclusão do curso técnico profissionalizante. Sendo assim, a grande maioria, $80,39 \%$ afirmou de forma positiva a este questionamento. Destes, $82,93 \%$ pretendem dar seguimento aos estudos na área das ciências agrárias. Sobre este questionamento predominou as jovens do sexo feminino, visto que a totalidade (100\%) responderam afirmativamente. Este resultado vai ao encontro de estudo realizado por Breitenbach e Corazza (2019), onde as autoras obtiveram os seguintes resultados ao estudar jovens rurais estudantes do Instituto Federal de Educação, Ciência e Tecnologia do Rio Grande do Sul: 54,7\% dos jovens pretendem continuar estudando e ingressar em ensino superior. Carneiro e Maluf (2003), já haviam constatado a ausência de interesse dos jovens rurais em ser agricultores em regiáo do Rio de Janeiro. Por esta razáo a continuidade dos estudos era tida como uma alternativa de não permanecer como agricultor.

\subsection{Entre o rural e o urbano: projetos profissionais dos jovens}

Nas geraçóes passadas, o projeto profissional dos jovens habitantes do meio rural consistia em permanecer no meio rural, ocupar o lugar dos pais (a partir do seu envelhecimento) na gestáo dos negócios e do patrimônio, com pouco estudo ou baixa qualificação profissional para a atividade agropecuária (SPANEVELLO et al., 2019). No caso das jovens mulheres, a ocupação estava assentada nas possibilidades de casar com um jovem agricultor e consistir moradia em sua propriedade.

Sendo assim, as práticas, habilidades e saberes eram repassados de geração em geração, isto é, entre pais e filhos, assim exigia-se que as crianças fossem inseridas no trabalho, sob a orientação dos pais como forma de socialização profissional e preparação para se tornar futuros agricultores ou donas de casa, no caso das mulheres (Marin et al., 2013).

Os resultados deste trabalho apontam um cenário em que um percentual dos entrevistados tem como projetos ficar no campo e seguir na atividade agropecuária, no entanto, outros projetos sáo identificados reforçando as novas dinâmicas do meio rural, na qual o rural é visto para além do local de moradia e trabalho. Em relação aos projetos profissionais futuros dos jovens (Tabela 2) constatou-se quatro cenários:

1) $27,45 \%$ pretende se instalar como agricultor no meio rural;

2) $35,29 \%$ dos jovens pretende residir no meio rural, com ocupações urbanas;

3) $21,57 \%$ pretendem residir e trabalhar no meio urbano com vínculo no rural;

4) $11,76 \%$ tem outras opçóes como projetos profissionais. 
Tabela 02: Projetos profissionais futuros dos jovens.

\begin{tabular}{l|c|c}
\hline \multicolumn{1}{c|}{ Projetos } & Frequência & Percentual \\
\hline Residir no meio rural, como agricultor & 14 & $27,45 \%$ \\
\hline Residir no meio rural e trabalhar no meio urbano & 18 & $35,29 \%$ \\
\hline Residir e trabalhar no meio urbano com vínculo no rural & 11 & $21,57 \%$ \\
\hline Outra situação & 6 & $11,76 \%$ \\
\hline Não respondeu & 2 & $3,92 \%$ \\
\hline
\end{tabular}

Fonte: Elaborado pelos autores (2020).

Analisando individualmente cada projeto observa-se que um percentual de entrevistados $(27,45 \%)$ tem como projeto profissional, após a conclusão do ensino técnico, residir no meio rural na condição de agricultor. Analisando a diferenças entre os sexos, observa-se existir mais rapazes $(28,26 \%)$ que moças $(20 \%)$ almejando este projeto profissional. Nestes casos, os jovens mantêm a dinâmica de suceder os pais na gestão da propriedade e dos negócios. Trata-se então de um processo de sucessão geracional que segue a lógica das geraçóes anteriores que todo filho de agricultor também é agricultor. Spanevello et al.(2014), revela que em propriedades aonde a sucessão tem mais chances de acontecer, os pais se antecipam a própria decisão dos filhos de sair. Neste caso, de acordo com os autores, os pais póem em marcha diferentes estratégias com vista a fomentar a permanência dos sucessores. De acordo com Matte et al.(2019), a decisão dos jovens em permanecer no campo é mais do que uma escolha e está atrelada as condições materiais e simbólicas que os jovens enfrentam para permanecer.

No entanto, é preciso ponderar que estes jovens permanecem numa condição distinta dos pais em relação a escolaridade, pois conforme Spanevello et al.(2019) os pais geralmente apresentam as séries iniciais enquanto os filhos têm avançado na escolaridade comparativamente aos pais. Este avanço permite que os jovens tenham maiores facilidade no domínio de técnicas e tecnologias necessárias a produção agropecuária, tornando-se peças chaves na modernização da produção agropecuária das propriedades com qualitativos econômicos, sociais e ambientais diferenciados. Ademais, segundo Signor (2019), tem-se assistido a crescente demanda pelo empreendedorismo no meio rural, em especial das novas geraçóes. Signor (2019) analisando estudos internacionais aponta que propriedades em que os jovens conseguem produzir a partir de estratégias sustentáveis, de agregação de valor e com denominação de origem podem representar maior inserção da produção no mercado com consumidores específicos gerando uma renda significativa e superior aos produtores convencionais, sendo esta uma motivação para o seguimento das propriedades.

Outro projeto profissional com maior expressão é residir no meio rural e trabalhar no meio urbano $(35,29 \%$ ), sendo uma opçáo para $20 \%$ das jovens mulheres e $36,96 \%$ dos jovens rapazes. Isso implica em ter o rural como local de moradia, mas náo como local de trabalho e geraçáo de renda. O morar e o trabalhar em locais distintos, segundo Zago (2016) "não se trata, de uma percepção de mão única: o campo que exclui é ao mesmo tempo idealizado por ser aquele que oferece melhor qualidade de vida". Para a autora, o meio rural é caracterizado como um local, com menos poluição, "alimentação mais saudável", mas é também um ambiente de adversidades, do trabalho "judiado, pesado, sem férias e 
de baixo rendimento". Sendo assim, os jovens se veem confrontados entre essas situações ambivalentes de melhor qualidade de vida, por um lado e de avaliação de perspectivas futuras restritas por outro lado (ZAGO, 2016).

Para Spanevello et al. (2011) residir no rural é também a possibilidade de permanecer na casa paterna e junto da família não perdendo o convívio familiar, além de não sobrecarregar o custo de vida com aluguel no meio urbano e demais despesas domésticas. Por outro lado, a renda urbana torna-se atrativa por ser fixa ao final de cada mês, situação diferente da agricultura. Spanevello (2008) ainda ressalta que os jovens gostam do rural, mas não de viver "do" rural, ainda que isso implique em ter um patrão e não ser o dono dos próprios negócios muitas vezes. Ademais, visto que estes jovens consideram a hipótese de ter o meio rural como local de moradia, com a opção por ocupaçóes urbanas geram dificuldades nos processos de sucessão familiar que leva em consideração a continuidade das atividades agrícolas.

Casagrande, Salvaro e Estevam (2012) ao analisar os projetos profissionais de jovens rurais inseridos em distintos cursos superiores separados por sexo, contataram que, em relação ao sexo masculino, $14 \%$ pretendem se estabelecer como agricultores, assim como apenas $14 \%$ pretendem trabalhar na área de formação no meio urbano, porém residir no meio rural. Por outro lado, a grande maioria, $72 \%$ pretende trabalhar na área de formação universitária no meio urbano e residir neste local. Resultados semelhantes foram evidenciados ao analisar os projetos profissionais das jovens do sexo feminino, no qual se constatou que a grande maioria (69\%), pretende trabalhar na área de formação universitária e residir no meio urbano. Enquanto que, 19\% afirmaram o desejo de trabalhar na área de formação universitária e permanecer no meio rural. Nenhuma jovem demonstrou interesse em se estabelecer no meio rural na agricultura.

Estes resultados diferem-se um tanto dos achados por Breitenbach e Corazza (2019), visto que $45,1 \%$ dos jovens pretendem retornar ao rural ao concluir seus cursos em formação, destes predomina os jovens do sexo masculino $(48,3 \%)$ em comparação as jovens do sexo feminino (35,7\%). Ainda, segundo Breitenbach e Corazza (2019), o incentivo financeiro recebido pelas atividades agropecuárias que são desenvolvidas na propriedade rural, evidenciaram que, o orgulho de ser filho de agricultores e estar ligado ao meio rural, a valorização das tradições familiares e da família e a alimentação e moradia baratas no campo estão entre os principais motivos para o jovem ficar no meio rural e certamente irão influenciar na decisão de serem ou não sucessores.

O projeto profissional que trata de residir e trabalhar no meio urbano (representado por $21,57 \%$ ) apresenta uma curiosidade que está justamente no tipo de ocupação que estes entrevistados desejam atuar: em ocupaçóes que prestam serviços ao rural e a produção agropecuária, tais como vendedores de insumos e máquinas agrícolas e prestadores de serviços de assistência técnica, ou seja, com vínculo no trabalho rural, ainda que de forma indireta. Em se tratando da assistência técnica, os jovens pretendem realizar cursos superiores em Agronomia e Medicina Veterinária para atuar posteriormente.

Outro aspecto sobre estes entrevistados foi o questionamento a respeito de assumirem a propriedade rural da família na condição de sucessores, a maior parte da amostra considerou como positiva a afirmação, $86,27 \%$. Ao analisar esta questão quanto ao sexo 
dos jovens, o estudo permitiu considerar que o interesse pelos jovens do sexo masculino é maior em assumir as propriedades dos pais na condição de sucessores, visto que 89,13\% responderam positivamente, quando comparadas as jovens do sexo feminino que tiveram como percentual $60 \%$. As jovens mulheres, em grande parte das situaçóes, são menos incentivadas a permanecer no meio rural, tendo menos oportunidades de participar nas decisóes da propriedade, impactando no menor interesse em serem sucessoras e buscam se desvincular do trabalho no meio rural quando tem a possibilidade de migraçáo urbana (Spanevello et al. 2019).

Dentre os jovens, que não pretendem assumir a propriedade rural de seus pais, os mesmos apresentaram duas razóes. A primeira refere-se ao fato de que outro irmão irá assumir a propriedade $(66,77 \%)$, enquanto a segunda é o desejo do jovem em ter outra atividade profissional (33,33\%).

Bednarikova, Bavorová e Ponkina (2016), por meio de uma leitura acerca dos estudos já realizados sobre as questóes que influenciam nas expectativas dos jovens rurais com educação agrícola argumentam alguns fatores que exercem influência sobre a motivação em migrar ou retornar as propriedades, dentre eles, destacam-se os antecedentes familiares, as expectativas de emprego, a qualidade de vida e questóes pessoais, dentre estas, questóes de gênero.

Os achados empíricos no presente estudo demonstraram o que já vêm sendo discutido na literatura ao longo do tempo que são as mudanças nos padróes sucessórios, visto que os jovens pretendem estabelecer-se no meio rural e nas propriedades, mas não necessariamente fazer destas suas atividades e fonte de renda principal. Como resultados, são frequentes os processos de envelhecimento no campo derivados da não permanência dos filhos na ocupação agrícola e na gestão das propriedades. Um destes estudos, realizado por Boscardin e Conterato (2017), com agricultores familiares sem sucessores no norte do Rio Grande do Sul, aponta que, mesmo não apresentando contornos ainda muito claros, os pais estão gerando outro modelo de passagem das propriedades, até então praticamente inexistente, agora sustentado na ideia que inclui ter herdeiros, mas não necessariamente sucessores. Tal constatação reside no fato de que os agricultores, em um primeiro momento, imprimem aos filhos um discurso negativo sobre a ocupação agrícola, especialmente devido às atividades agrícolas penosas, impossibilidade de férias e finais de semana, entre outras razóes, não querendo que os filhos sejam agricultores. Desta forma, estimulam os filhos a sair do meio rural em busca de oportunidades mais promissoras no meio urbano. Posteriormente, num segundo momento, quando questionados em relação ao destino de suas propriedades diante da não sucessão, os agricultores manifestam desejo de não vender a propriedade, mas sim deixar aos filhos como herança. Estas contradiçōes denotam que os pais não desejam que os filhos permaneçam na agricultura, mas sim que recebam sua terra como herança, o que demonstra haver uma desvinculação entre a sucessão geracional propriamente dita e exploração agrícola em si (BOSCARDIN; CONTERATO, 2017).

Nestes casos, propriedades com presença de herdeiros, porém não sucessores, reside a possibilidade de manutenção da produção agrícola, porém aumentam as chances de incorporaçáo destas propriedades a propriedades de maior porte. Ou ainda, reside a possibilidade destas propriedades passarem a serem usadas em atividades não agrícolas, nos 
casos de uso para lazer, sobretudo nos casos em que os filhos já traçaram seu futuro em atividades com olhos voltados para fora do meio rural e da própria agricultura.

Outro cenário apontado pelos entrevistados (correspondendo a 11,76\% dos jovens com predominância de mulheres) está em seguir os estudos visando projetos profissionais voltados ao trabalho urbano. Entre os cursos superiores citados estão os ligados à área de educação (Ciências Biológicas e Educação Física), da saúde (Medicina) e da tecnologia (Engenharia Mecânica). Este grupo visualiza seus projetos futuros sem relação com o meio rural, tanto na questão de residência, como na questão de atuação como agricultoras ou em empregos urbanos ligados à área agrícola. Nestes casos, são jovens que desejam buscar uma graduação em áreas distintas do conhecimento sem estar necessariamente ligado ao curso técnico em agropecuária. Por isso, o rural passa a fazer parte apenas como o local de origem e visitação da família.

\section{CONCLUSÓES}

Este artigo teve como objetivo analisar os projetos profissionais de jovens estudantes de curso técnico em Agropecuária e partir dos dados coletados e das análises realizadas verifica-se que, apesar dos jovens ter origem no rural, a maior parte dos entrevistados busca um projeto voltado a ocupação urbana. Ou seja, embora estejam vinculados a um curso voltado a formação agropecuária a maior parte deles não pretende ocupar-se de atividades agrícolas futuramente, ou seja, são jovens que estão buscando a qualificação educacional para atuarem em atividades no meio urbano. No entanto, ainda que a preferência seja por ocupaçóes urbanas, o local de moradia da maioria é o rural. Nestes casos, os jovens optam por residir no rural (tanto os que desejam ser agricultores com os que pretendem trabalhar no meio urbano).

Ainda que este artigo trate de uma amostra de jovens pertencentes a uma única escola dentro de um universo especifico (não passível de generalizaçóes), é possível constatar que o rural é importante aos jovens por ser o seu local de origem, de convívio com a família e de iniciação ao mundo do trabalho. A escolha pelo urbano pode estar atrelada as desvantagens do rural frente ao urbano em termos de renda fixa, penosidade do trabalho, entre outras causas que tornam o urbano mais atrativo. Neste caso, outros estudos com jovens estudantes de escolas agrícolas podem aprofundar estas questões e gerar conclusóes mais bem fundamentadas.

\section{REFERÊNCIAS}

ANJOS, F.S.; CALDAS, N.V. O futuro ameaçado: o mundo rural face aos desafios da masculinização, do envelhecimento e da desagrarização. Ensaios FEE, Porto Alegre, v.26, n.1, p.661- 694, jun. 2005. Disponível em: <http://www.scielo.br/pdf/cr/ v40n2/ a469cr2481.pdf>. Acesso em: 25 out. 2019.

BEDNARÍKOVÁ, Z.; BAVOROVÁ, M.; PONKINA, E.V. Migration motivation of agriculturally educated rural youth: the case of Russian Siberia. J. Rural Stud, v.45, p 99- 
111, 2016. Disponível em: <https://doi.org/10.1016/j.jrurstud.2016.03.006>. Acesso em: 01 nov. 2019

BREITENBACH, R.; CORAZZA, G. Formação profissional e a relação com a sucessão geracional entre jovens rurais, Brasil. Revista Latinoamericana de Ciencias Sociales, Nińez y Juventud, v. 17, n. 2, p. 1-34, 2019. Disponível em: http://dx.doi. org/10.11600/1692715x.17212. Acesso em: 01 fev. 2020.

BOSCARDIN, M.; CONTERATO, M. A. As mudanças nos padróes sucessórios e suas implicaçóes no destino das propriedades entre agricultores familiares no norte do Rio Grande do Sul. Estudos Sociedade e Agricultura, vol. 25, n. 3 , p. 671-695, 2017. Disponível em: < https://doi.org/10.36920/esa-v25n3-9>. Acesso em: 15 dez. 2019

CASAGRANDE, D. P.; SALVARO, G. I. J.; ESTEVAM, D. O. Projetos Profissionais de jovens universitários/as que residem no meio rural: estudo de caso dos/as jovens do município de Meleiro, SC. Interaçóes (Campo Grande), vol.13, n.2, p. 261-271, 2012. http://dx.doi.org/10.1590/S1518-70122012000200012. Acesso em: 01 nov.2019

\section{CAMARANO, A. A.; ABRAMOVAY, R. Exxodo rural, envelhecimento e}

masculinização no Brasil: panorama dos últimos 50 anos. Rio de Janeiro: IPEA, 1999. Disponível em: <http:/www.dominiopublico.gov.br/download/ texto/td_0621.pdf>. Acesso em: 25 out. 2019.

CARNEIRO, M. J. Juventude rural, projetos e valores. In.: Abramo, H. W.;Branco, P. P. M.(Org.). Retratos da Juventude Brasileira: Análises de uma pesquisa Nacional. São Paulo: Fundação Perseu Abramo, 2005. p. 243 - 261.

CARNEIRO, M. J. O ideal rurbano: campo e cidade no imaginário dos jovens rurais. In: SILVA, F. C. T (Org.). Mundo rural e política: ensaios interdisciplinares. Rio de Janeiro: Campus, 1999. p. 97-117.

\section{CARNEIRO, M. J.; MALUF, S. R. Para além da produção: multifuncionalidade e} agricultura familiar. Rio de Janeiro: Mauad, 2003.

CORADINI, L. Desigualdades de gênero e a reprodução social da agricultura familiar no Rio Grande do Sul. In: Saláo de Iniciaçáo Científica (20: 2008 out. 20-24: Porto Alegre, RS). Livro de resumos. Porto Alegre: UFRGS, 2008.

FOGUESATTO, C. R; MACHADO J. A. D. A tomada de decisão dos jovens no processo migratório rural urbano no Brasil: panorama entre 1970 e 2010. Enciclopédia biosfera. Goiânia, v.11 n.21, p. 2793-2802, 2015. Disponível em: < http://www.conhecer. org.br/enciclop/2015b/multidisciplinar/a\%20tomada\%20de\%20decisao.pdf>. Acesso em: 25 out. 2019 
KAYEMA, A. Desenvolvimento rural: conceitos e aplicação ao caso brasileiro. Porto Alegre: Editora da UFRGS: Programa de Pós-Graduação em Desenvolvimento Rural, 2008.

MARIN, J. O. B.; SCHNEIDER, S.; VENDRUSCOLO, R.; SILVA, C. B. De C. O Problema do Trabalho Infantil na Agricultura familiar: o caso da produção de tabaco em Agudo-RS. Revista de Economia e Sociologia Rural, v. 50, n. 4, p. 763-786, Out/Dez 2012 - Impressa em Janeiro de 2013.

MATTE, A.; MACHADO, J. A. D. Tomada de decisão e a sucessão na agricultura familiar no sul do Brasil. Revista de Estudos Sociais, v. 18, n. 37, p. 130-151, 2016. Disponível em:<http://dx.doi.org/10.19093/res.v18i37.3981>. Acesso em: 01 nov. 2019

MATTE, A.; SPANEVELLO, R. M.; LAGO, A.; ANDREATA, T. Agricultura e pecuária familiar: (des) continuidade na reprodução social e na gestão dos negócios. Revista Brasileira de Gestáo e Desenvolvimento Regional, v. 15, p. 19-33, 2019. Disponível em: <https://www.rbgdr.net/revista/index.php/rbgdr/article/view/4317>. Acesso em: 01 fev. 2020

MORAES, M.; BINOTTO, E.; BORGES, J. A. Identifying beliefs underlying successors' intention to take over the farm. Land Use Policy, v. 68, p. 48-58, 2017. Disponível em: <https://doi.org/10.1016/j.landusepol.2017.07.024> .Acesso em: 01 nov.2019

SALVARO, G. I. J.; QUADROS, S. M.; ESTEVAM, D.O. Projetos profissionais de estudantes de um curso técnico em Agropecuária. Psicologia e Sociologia, v.28, n.2, p.309-319, 2016. http://dx.doi.org/10.1590/1807-03102016v28n2p309. Acesso em: 15 dez. 2020

SILVA, J. G. da. O novo rural brasileiro. Campinas: Editora da Unicamp, 1999. (Coleção Pesquisas 1).

SIGNOR, C.P. Empreendedorismo rural: intenções empreendedoras dos jovens acadêmicos da área de ciências agrárias. Palmeira das Missóes: UFSM, 2019. 111 p. Dissertação (Mestrado em agronegócios) - Programa de Pós-Graduação em Agronegócios, Universidade Federal de Santa Maria, Palmeira das Missões, 2019.

SPANEVELLO, R.M. A dinâmica sucessória na agricultura familiar. Porto Alegre: UFRGS, 2008.236 p. Tese (Doutorado em Desenvolvimento Rural) - Programa de Pós Graduação em Desenvolvimento Rural, Universidade Federal do Rio Grande do Sul, Porto Alegre, 2008.

SPANEVELLO, R.M.; AZEVEDO, L.F.; VARGAS, L.P.; MATTE, A. A migração juvenil e implicaçóes sucessórias na agricultura familiar. Revista de Ciências Humanas, v. 45, n.2, p. 291-304, 2011. DOI: https://doi.org/10.5007/2178-4582.2011v45n2p291. Acesso em: 25 out.2019 
SPANEVELLO, R. M.; LAGO, A.; CHRISTOFARI, L. F; ANDREATA, T. As estratégias para manter a sucessão em estabelecimentos familiares. In: RENK, A; DORIGON, C. (Org.). Juventude Rural, cultura e mudança social. 5ed. Chapecó: Argos, 2014, p. 163-188.

SPANEVELLO, R. M.; DUARTE, L. C.; SCHNEIDER, C. L. C.; MARTINS, S. P. Agroindústrias rurais familiares (ARFs) como estratégia de reprodução socioeconômica da agricultura familiar nos municípios de Santo Augusto e Campo Novo - RS. Redes (Santa Cruz do Sul. Online), v.24, n.3, p.198-216, 2019. Disponível em: 10.17058/redes. v24i3.14125. Acesso em: 01 fev.2020

SPANEVELLO, R.M.; DOEGE, A. M.; DREBES, L.; LAGO, A. Mulheres Rurais e Atividades Não Agrícolas no Âmbito da Agricultura Familiar. Desenvolvimento Em Questão, v. 17, n. 48, p. 250-265, 2019. Disponível em: https://doi.org/10.21527/22376453.2019.48.250-265. Acesso em: 01 fev.2020

SPANEVELLO, R.M.; MOREIRA, S.L.; BOSCARDIN, M. Dinâmica Demográfica da população rural: o Caso do Corede Alto Jacuí, Rio Grande do Sul. Nucleus, v.15, n.2,2018. http://dx.doi.org/10.3738/1982.2278.2912. Acesso em: 01 fev.2020

TROIAN, A.; BREITENBACH, R. Jovens e juventudes em estudos rurais do Brasil. Interaçóes (Campo Grande), v. 19, n. 4, p. 789-802, 2018. Disponível em: http:// dx.doi.org/10.20435/inter.v19i4.1768. Acesso em: 25 out.2019

VELHO, G. Antropologia das Sociedades Complexas. Projeto e metamorfose, Jorge Zahar (ed), 3a Edição. Rio de Janeiro, 2003.

WEISHEIMER, N. A situação juvenil na agricultura familiar. Porto Alegre: UFRGS, 2009.331 p. Tese (Doutorado em Sociologia) - Programa de Pós Graduação em Sociologia, Universidade Federal do Rio Grande do Sul, Porto Alegre, 2009.

ZAGO, N. Migração rural - urbana, juventude e ensino superior. Revista Brasileira de Educaçáo, v. 21, n. 64, p. 61-78, 2016. Disponível em: <https://doi.org/10.1590/S1413$24782016216404>$. Acesso em: 25 out. 2019. 